\title{
Effect of tidal currents and tidal stage on estimates of bed size in the kelp Nereocystis luetkeana
}

\author{
Kevin Britton-Simmons ${ }^{1, *}$, James E. Eckman ${ }^{2}$, David O. Duggins ${ }^{1}$ \\ ${ }^{1}$ University of Washington, Friday Harbor Laboratories, 620 University Road, Friday Harbor, Washington 98250, USA \\ ${ }^{2}$ Office of Naval Research, 875 N. Randolph Street, Arlington, Virginia 22203-1995, USA
}

\begin{abstract}
Aerial or overhead photography is a technique commonly used to measure spatiotemporal variability in surface canopy kelps. To evaluate potential biases in this technique, we used elevated (shore-based) oblique angle photography coupled with in situ measurements of currents and tides to sample 4 independent Nereocystis luetkeana beds at sites adjacent to San Juan Island (Washington State, USA) in 2004 and 2005. Data were collected at high frequency (every $10 \mathrm{~min}$ ) to quantify the effects of tidal height and tidal currents on the amount of $N$. luetkeana visible at the surface. Effects of tidal height were highly significant in all 6 time series. Current significantly affected apparent bed size in 5 of the 6 time series, although the magnitude of the effect varied among sites. $N$. luetkeana beds decrease in apparent size as current velocity increases and as tidal level increases. Currents can fluctuate rapidly, changing by many $10 \mathrm{~s}$ of $\mathrm{cm} \mathrm{s}^{-1}$ over periods as short as $10 \mathrm{~min}$, due in large part to interactions of tides with local topography and bathymetry close to shore, where kelp beds are typically found. As a result, currents can introduce significant variability to estimates of kelp population size collected by remote sensing techniques.
\end{abstract}

KEY WORDS: Remote sensing $\cdot$ Aerial photography $\cdot$ Shore-based photography $\cdot$ Kelp $\cdot$ Bed size estimates $\cdot$ Tidal currents $\cdot$ Tidal height $\cdot$ Nereocystis luetkeana

\section{INTRODUCTION}

Kelp provide important habitat for many marine species (Ghelardi 1971, Duggins 1980, Carr 1983) and are a key source of carbon in coastal food webs (Dunton \& Shell 1987, Duggins et al. 1989). Moreover, in some regions kelp are harvested commercially and thus have considerable economic value. Because of their ecological and economic value there is tremendous interest in monitoring the abundance and dynamics of nearshore kelp populations, and a wide variety of methods have been used to achieve this goal.

One of the most commonly used methods for monitoring nearshore surface-canopy kelp is aerial photography, a technique that dates back to the 1920s (Guillaumont et al. 1997). This aerial approach is especially popular for monitoring Macrocystis and Nereocystis, the 2 largest kelp genera found along the west coast of North America, because these taxa form floating canopies at the water surface that are visible from a great distance. Several different photographic techniques are used, including infrared and color photography (Deysher 1993, Schoch 2001, Berry et al. 2005), but all photographic monitoring techniques involve taking photos of kelp beds from aircraft and analyzing the images to quantify the amount of kelp floating at or very near the water surface. Although these methodologies do not allow the number of individuals to be quantified, they do yield metrics of kelp abundance (typically $\mathrm{m}^{2}$ or ha of kelp) that should be proportional to population size. Photographing the same kelp beds repeatedly over time (typically from year to year) in principle allows the population dynamics of these species to be assessed. In addition, kelp population data derived from aerial photographs are used in population and community level studies of species associated with kelp (e.g. Kvitek et al. 1989, Tegner et al. 2001). 
Despite the widespread use of aerial photographic methods, little quantitative information is available about how in situ environmental conditions influence the accuracy of data obtained using these techniques. Typically the goal is to capture the maximal extent of the bed (Schoch 2001, Berry et al. 2005), and the methodologies employed often address some of the most obvious potential sources of variation. For example, in Alaska and Washington, agencies restrict their sampling to low tidal stages (Schoch 2001, Berry et al. 2005), an explicit recognition that tidal stage (i.e. water depth) potentially affects the portion of the bed visible at the surface. Many other factors, including specular reflectance (Austin \& Adams 1978), contrast (Deysher 1993), seasonal phenology (Schoch 2001, Van Wagenen 2001), atmospheric clarity (O'Neill et al. 1995), wind (Dobson et al. 1995, Guillaumont et al. 1997), turbidity (Deysher 1993, Guillaumont et al. 1997), co-occurring species (North et al. 1993), and currents (North et al. 1993, Schoch 2001), are acknowledged as likely influences on these techniques, and provisions are often made to account for some of these factors either during the sampling or during processing of images after their acquisition. Atmospheric effects on remote sensing have been studied extensively (reviewed by O'Neill et al. 1995), but quantitative studies on the effects of these other potential sources of error are generally lacking (but see Deysher 1993).

We are especially concerned with the role played by currents, a potentially complicating environmental factor that has not been evaluated explicitly. In the Northeast Pacific, aerial photography is used for monitoring coastal kelp beds in Washington and Alaska (Schoch 2001, Van Wagenen 2004, Berry et al. 2005). The primary focus of these monitoring efforts is the kelp species Nereocystis luetkeana, although Macrocystis integrifolia is also photographed in some areas (Schoch 2001). In this region, tidal currents are a dominant physical force in nearshore waters (Eckman et al. 1989, 2003). Casual observations made while SCUBA diving in Nereocystis luetkeana beds in Washington suggested that there can be considerable variation in the strength of tidal currents over very short periods of time. In addition, during periods of intense pulses of current, we noticed that many $N$. luetkeana plants that normally float at the surface become subducted below the surface due to fluid drag operating on the flexible stipe, only to reappear again at the surface when the current diminishes. Plants that are submerged deeply enough due to currents would not be detected by aerial photography. Sampling methodologies that rely on reflectance in the near-infrared (NIR) region of the spectrum will be especially vulnerable to this problem because the NIR reflectance of brown algae decreases rapidly within a few centimeters of the surface (Augenstein et al. 1991, Guillaumont et al. 1997). Based on our field observations, we suspected that short-term fluctuations in current might influence estimates of kelp bed size based on aerial photography. No previous study has explicitly investigated how tidal currents affect size estimates of $N$. luetkeana or any other surface canopy seaweed, based on aerial photography.

In this study we used oblique angle, shore-based photography (an economical alternative to aerial photography) to investigate how tidal currents and tidal stage affect the amount of Nereocystis luetkeana visible at the surface in photographs. If short-term fluctuations in tidal currents have substantial effects on apparent kelp bed size (as measured from photos) this result would have important implications for any agency or individual using this method to monitor marine algae in regions where tidal currents occur.

\section{MATERIALS AND METHODS}

Collection of field data. Four independent kelp beds were studied at sites adjacent to San Juan Island (Washington State USA) in 2004 and 2005 (Fig. 1, Table 1). The study sites were separated by a minimum distance of $0.9 \mathrm{~km}$. Sites studied during 2004 included Landbank (29 July), South Beach (29 August), and Deadman Bay (24 September). During 2005 we studied beds at 1 new site, Cattle Pass (19 August), and resampled both Landbank (5 August) and Deadman Bay (6 August). Thus, we carried out 6 separate studies of kelp bed responses to flow and tidal stage. At all 4 study sites the shoreline is steeply sloped, which allowed us to take photos of the Nereocystis luetkeana beds from above, at an oblique angle, using a digital camera (Nikon Cool Pix 8700, 8.0 Megapixel) mounted on a tripod.

In each study, surface currents impacting the kelp bed were measured using a single S4 Current Meter (InterOcean Systems) suspended $1.5 \mathrm{~m}$ below the surface using a large float anchored in place near the periphery of the bed. At the first site studied in 2004 (Landbank) we placed the S4 current meter on the inside (landward) of the Nereocystis luetkeana bed near its center. During that deployment we observed (from shore) that strong currents often occurred at the outside edge of the bed while the inside of the bed experienced only weak currents (sometimes moving in the opposite direction). Based on these observations, we decided to place the current meter on the outer edge of the center of the $N$. luetkeana bed during all subsequent deployments.

To provide a scale reference in photos for image processing, a floating bar $4.75 \mathrm{~m}$ in length was attached to 


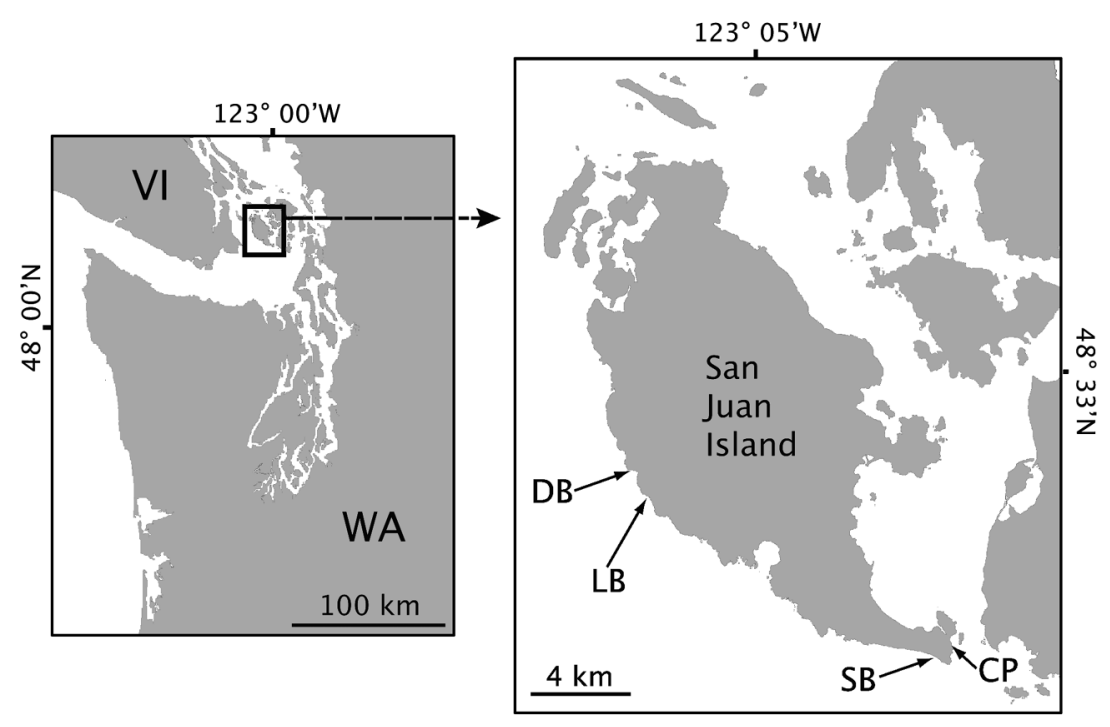

Fig. 1. Nereocystis luetkeana study sites on San Juan Island, Washington State, USA. DB: Deadman Bay; LB: Landbank; SB: South Beach; CP: Cattle Pass
Analysis of images. Prior to analysis, all images were edited using Photoshop CS to improve the contrast between kelp and water. In addition, any nonkelp features in the images that could complicate the analysis were erased (e.g. land and trees in the near-field periphery, waves). We used the software Sigmascan Pro (version 5.0, SPSS) to analyze each image and quantify the area at the water surface that was covered by Nereocystis luetkeana. To accomplish this, each image was first converted to grayscale so that the kelp appeared darker than the surrounding water. Next, the range of pixel intensities to be used in the measurement was gradually increased until virtually all kelp in the image was included. In some images, non-kelp features (such as reflections of capillary waves) began to be picked up before all the $N$. luetkeana had been included. In

the S4 surface float and allowed to trail downstream (typically alongshore [along an isobath], toward 1 side or the other in photos). The scale bar was visible in every photo, regardless of current direction or speed. Tidal height was measured using a Dobie Wave Gauge (NIWA Instrument Systems) anchored to a weighted frame that was placed on the seafloor in close proximity to the bed being sampled.

Internal clocks in the camera, current meter, and tide gauge were synchronized prior to each deployment. During each study we measured current velocity (1 min average) and tidal height (1 min average), and took a digital photo of the kelp bed simultaneously at 10 min intervals for the duration of daylight on 1 day. A typical sample period began just prior to low tide (in the morning) and ended just after high tide (late afternoon). However, the exact time period sampled varied among sites depending on the magnitude of the exchange and the timing of the tides. All sampling was done during spring tide series. these cases, the pixel range was increased just until the first non-kelp features were included and the image was processed using that intensity range. Fig. 2 shows examples of 2 images, including the overlay produced by Sigmascan that indicates the location of kelp identified during the image analysis procedure. Once the appropriate pixel intensity range was chosen, the scale of the image was calibrated using the floating scale bar, and the software then calculated the 'apparent area' of the highlighted kelp, based on the lateral scale. Repeated analysis of 4 images taken at a variety of current speeds and tidal heights indicated that this methodology had relatively small measurement error. The average difference between bed size estimates when photos were analyzed twice was $3.5 \mathrm{~m}^{2}$, a relatively small difference given the large size of these beds (100s to $1000 \mathrm{~s}$ of $\mathrm{m}^{2}$ ) and the large temporal fluctuations we observed.

This 'apparent area' was corrected to account for a bias inherent to the oblique view of the photographs

Table 1. Summary of kelp bed properties and key sampling details. Fringing, continuous beds were directly adjacent to the shoreline and continued along the shore at both ends of the section that we photographed. Offshore, discrete beds did not directly abut the shoreline, allowing water to pass on both sides of the bed. This latter type of bed was completely captured in our photographs. $d_{\mathrm{V}}$ : camera elevation $(\mathrm{m}) ; d_{\mathrm{H}}$ : horizontal distance from camera $(\mathrm{m})$

\begin{tabular}{|lcllllll|}
\hline Site & Latitude & \multicolumn{1}{c}{ Longitude } & Kelp bed type & $d_{\mathrm{V}}$ & $d_{\mathrm{H}}$ & Angle $\left(^{\circ}\right)$ & Sample date(s) \\
\hline Landbank & $48^{\circ} 30.179^{\prime} \mathrm{N}$ & $123^{\circ} 8.548^{\prime} \mathrm{W}$ & Offshore, discrete & 44 & 443 & 5.7 & $29 \mathrm{Jul} 04 ; 5 \mathrm{Aug} 05$ \\
South Beach & $48^{\circ} 27.013^{\prime} \mathrm{N}$ & $122^{\circ} 58.103^{\prime} \mathrm{W}$ & Offshore, discrete & 22 & 200 & 6.3 & 29 Aug 04 \\
Deadman Bay & $48^{\circ} 30.762^{\prime} \mathrm{N}$ & $123^{\circ} 8.860^{\prime} \mathrm{W}$ & Fringing, continuous & 22 & 129 & 9.7 & 24 Sep 04; 6 Aug 05 \\
Cattle Pass & $48^{\circ} 27.097^{\prime} \mathrm{N}$ & $122^{\circ} 57.668^{\prime} \mathrm{W}$ & Fringing, continuous & 22 & 123 & 10.1 & 19 Aug 05 \\
\hline
\end{tabular}


in the onshore-offshore direction. A geometric and trigonometric analysis (see Appendix 1) indicated that the true area of exposed kelp visible by oblique angle photos can be calculated by dividing the 'apparent area' by $\sin \theta$, where $\theta$ is the angle between the line of the camera view and sea level. This corrected value, called 'Kelp Area,' is reported here and used in all analyses. We recognize that there are some additional errors in our area estimates due to: (1) changes in tidal height (i.e. tidal changes in $d_{\mathrm{V}}$ referred to in Appendix 1) during each series of photos, and (2) use of a single linear scale assigned to all locations in photographs. However, we believe the amount of error involved is small, and of little importance, given the magnitude of changes in bed size that we detected (see
Appendix 1). In addition, since the location of the bed, the camera, and the scaling factor were all fixed (for each time series), the error was effectively constant in all estimates of bed area at each site. Thus, this error should not affect our analysis of the influence of tidal height and current speed on apparent kelp bed size.

The photo series from Deadman Bay (2004 and 2005) and Cattle Pass (2005) were compromised because intermittent fog on the days those sites were sampled reduced the quality of some images; we excluded the worst images from the analysis. Furthermore, at Deadman Bay in 2004 many of the remaining images had non-uniform lighting due to atmospheric conditions such that the right side was much darker than the left. We cropped the images in half from this series, using

$11: 20 \mathrm{am}$, Current speed $=51.8 \mathrm{~cm} \mathrm{~s}^{-1}$, Tidal height $=-0.16 \mathrm{~m}$, Bed size $=132.1 \mathrm{~m}^{2}$
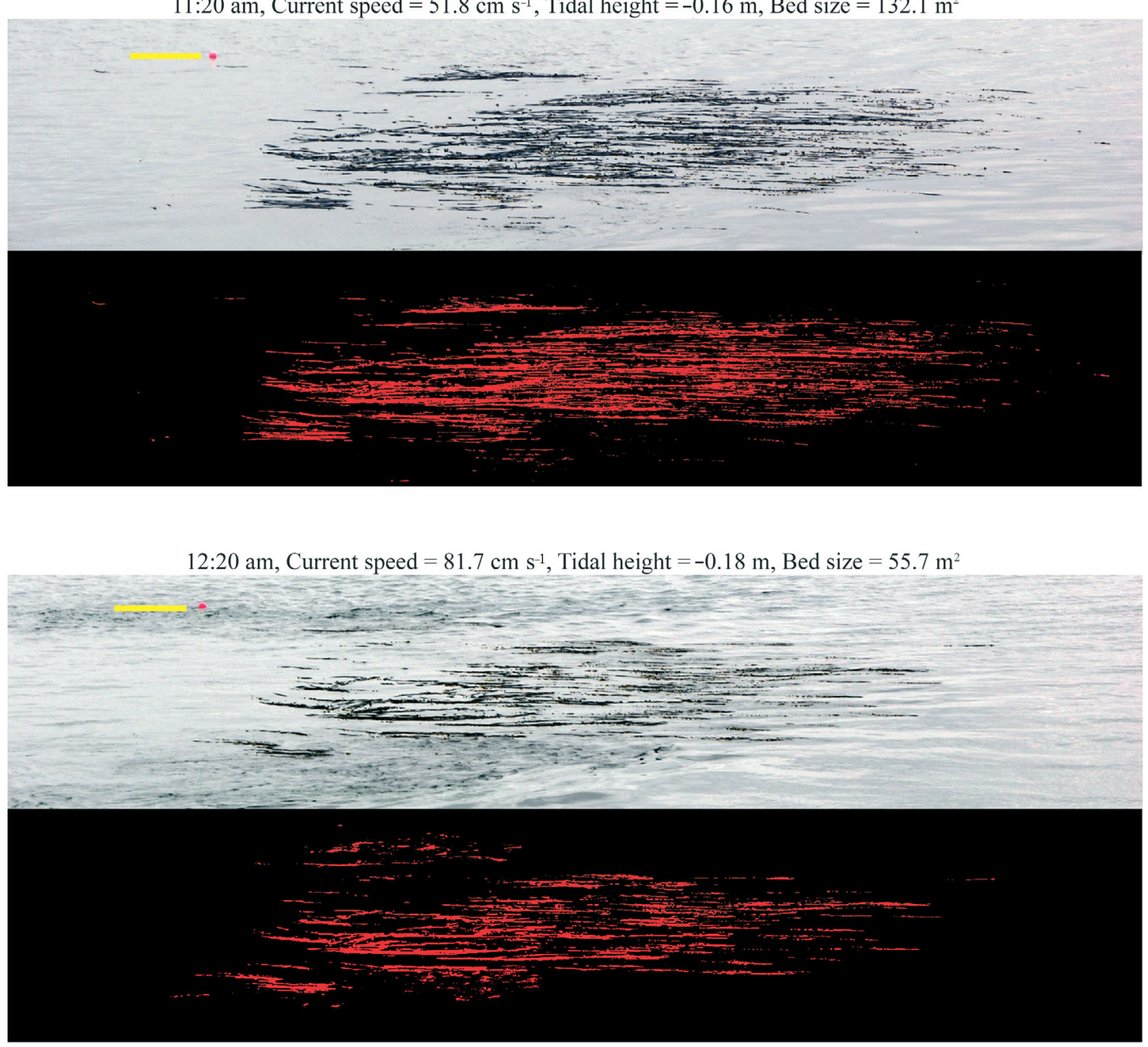

Fig. 2. Images of the South Beach kelp bed, taken $1 \mathrm{~h}$ apart, that indicate a decrease in bed size of more than $50 \%$. The floating scale bar $(4.75 \mathrm{~m})$ has been highlighted in yellow. The red overlay image below indicates the kelp that was identified and measured by the image analysis software 
the left half only for our image analysis and discarding the darker right half of all images.

Statistical analyses. Because tidal height and surface currents covary at our sites, we included both of these factors in our statistical analyses. We carried out 3 types of analysis to detect and separate effects of tidal height and current speed on Kelp Area. (1) We used linear multiple regression on the 6 series to determine whether current speed and tidal height (as independent variables) were significantly correlated with Nereocystis luetkeana bed size (dependent variable). (2) We calculated partial correlation coefficients to characterize the amount of variation in bed size attributable to current versus tidal height. A partial correlation coefficient measures the correlation between any pair of variables when values of other specified covariables are held constant (Sokal \& Rohlf 1981). For example, this statistic allows us to calculate the correlation between Kelp Area and surface current strength while holding constant the effects of tidal height. The significance of any partial correlation coefficient can be determined by calculating the appropriate Student's $t$-statistic (Sokal \& Rohlf 1981). (3) For each data series we examined the correlation between Kelp Area and current speed on the fraction of the data set restricted to a narrow window around mean lower low water (MLLW). The justification for this analysis is that aerial photography of kelp beds is typically done close to low tide in order to minimize the error associated with tidal stage (Schoch 2001, Van Wagenen 2004). We considered only the portion of our data sets falling at or below +1.2 $\mathrm{m}$ above MLLW. This interval includes all sampling windows used by the Washington Department of Natural Resources on kelp mapping projects between 1989 and 2005 (H. Berry pers. comm.). Relationships between Kelp Area and current speed were evaluated via linear or log-log regression (the latter defining a power function) depending on the shape of the empirical relationship.

\section{RESULTS}

\section{General patterns of variation}

Fig. 3 illustrates temporal patterns of variation in Kelp Area, current speed, and tidal height for each series. These data indicate several noteworthy patterns and differences among sites. It is clear that current speed at most sites exhibits tremendous variability over relatively short time periods (10s of minutes), and that the pattern of spikes and dips in current speeds, relative to tidal stage, is not consistent among sites. For example, at South Beach, current speed increases rapidly after low water to speeds $>50 \mathrm{~cm} \mathrm{~s}^{-1}$ that are sustained until near high water (Fig. 3A), whereas at Landbank and Deadman Bay the flood tide is characterized by sustained periods of slow flow punctuated by brief (10 to $30 \mathrm{~min}$ ) episodes of strong currents (Fig. 3B-E). The site at Cattle Pass (Fig. 3E) remains calm throughout flood tide, and stronger currents (>50 $\mathrm{cm} \mathrm{s}^{-1}$ ) occur very quickly only near high tide. Landbank experiences periods of significant currents prior to and at low tide, whereas other sites do not.

The area of kelp visible at the surface clearly responds to the covariation between currents and tidal stage. At South Beach (Fig. 3A), Kelp Area falls off quickly as currents rise after low tide. Kelp effectively disappear from the surface by the time current speed reaches $100 \mathrm{~cm} \mathrm{~s}^{-1}$, about one-third of the time between low and high water. At high water, the kelp bed starts to re-emerge at the surface when current speeds decrease below $80 \mathrm{~cm} \mathrm{~s}^{-1}$. At Landbank (Fig. 3B,E) kelp beds were relatively large before and at low water and declined in size monotonically as the tide rose. However, overlain on this pattern were shortterm fluctuations in kelp area that reflected fluctuations in current speed. For example, in 2004 (Fig. 3B) large and rapid spikes in currents on the rising tide were associated with precipitous drops in bed size, whereas rapid decreases in currents were associated with increases in bed size. Similar reflections occurred in 2005 (Fig. 3E). Likewise, in both years at Deadman Bay (Fig. 3C,D) a large kelp bed visible before and at low water decreased in size during flood tide, with short-term fluctuations in bed size reflecting changes in current speed. However, at Deadman Bay large spikes in current velocity were rarer than at Landbank. Finally, at Cattle Pass the kelp bed declined in size with the rising tide (Fig. 3F). Strong currents were never observed during flood tide and occurred only at (and after) high water when the bed had already virtually disappeared from the surface.

\section{Statistical analyses}

As expected, multiple regression analysis showed a highly significant effect of tidal height on Kelp Area in all 6 time series (Table 2). This analysis also showed that effects of current on Kelp Area were significant in 5 of the 6 time series. The partial regression coefficients for both variables were negative, indicating that Nereocystis luetkeana beds decrease in apparent size as current velocity and tidal height increase. In the one instance where current velocity was not significant (Cattle Pass in 2005), currents remained low $(<40 \mathrm{~cm}$ $\mathrm{s}^{-1}$ ) for almost the entire time series (Fig. 3F). Current and tidal height combined explained a large amount 

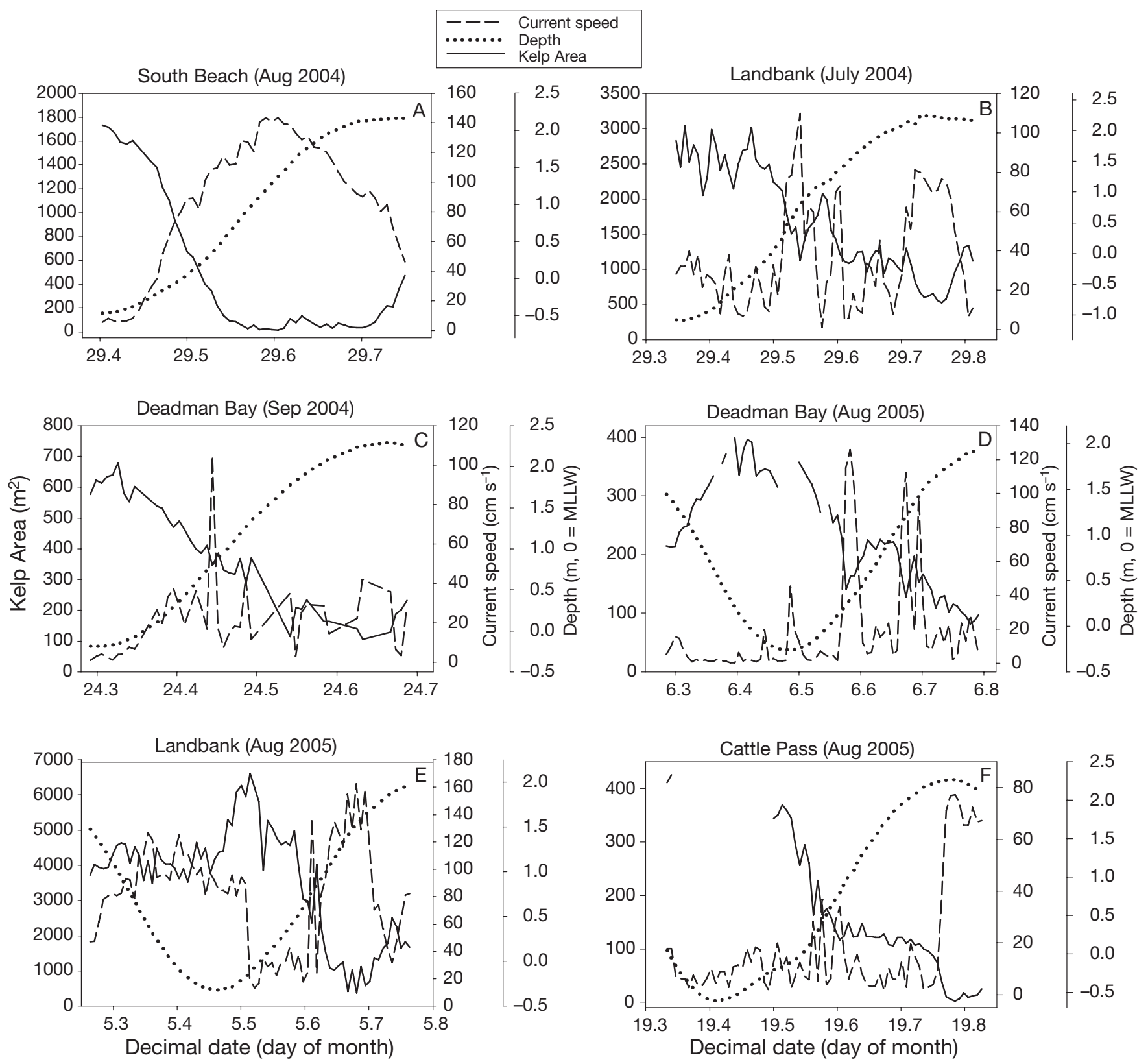

Fig. 3. Current velocity, water depth, and measured Nereocystis luetkeana bed size (based on shore-based photographs) on 6 sample dates. All 3 response variables were measured simultaneously at 10 min intervals. Gaps in the Kelp Area data occurred

in some data series because fog and/or glare rendered some images impossible to analyze. MLLW: mean lower low water

(74 to $95 \%$ ) of variation in the apparent Kelp Area (Table 2).

The partial correlation analysis (Table 2) allows us to quantify the percentage of variation in Kelp Area that would be attributable to current speed or tidal height, if effects of the other variable were held constant. This analysis shows that effects of tidal height were highly significant $(p<0.001)$ in all 6 time series, and that if effects of currents were controlled, variability in tidal height would have explained between $67 \%$ (at Landbank in 2005) and 95\% (at Deadman Bay in 2004) of observed variability in Kelp Area. Effects of current speed were highly significant $(\mathrm{p}<0.001)$ in 5 of the 6 time series (the exception again being Cattle Pass in 2005). If effects of tidal height were controlled, variability in current speed would have explained between $25 \%$ (at Deadman Bay in 2004) and $86 \%$ (at South Beach in 2004) of observed variability in Kelp Area. 
Table 2. Results of multiple regression and partial correlation analyses. ${ }^{*} \mathrm{p}<0.05{ }^{* * *} \mathrm{p}<0.001$

\begin{tabular}{|c|c|c|c|c|c|c|c|c|}
\hline \multirow[t]{3}{*}{ Site } & \multirow[t]{3}{*}{ Date } & \multicolumn{3}{|c|}{ Multiple regression analysis } & \multicolumn{4}{|c|}{ Partial correlation analysis } \\
\hline & & \multirow{2}{*}{\multicolumn{2}{|c|}{$\begin{array}{l}\text { Partial regression coefficients } \\
\text { Currents } \quad \text { Depth }\end{array}$}} & \multirow[t]{2}{*}{$\mathrm{R}^{2}$} & \multicolumn{2}{|c|}{$\begin{array}{l}\text { Current effect } \\
\text { (depth constant) }\end{array}$} & \multicolumn{2}{|c|}{$\begin{array}{l}\text { Depth effect } \\
\text { (current constant) }\end{array}$} \\
\hline & & & & & $\mathrm{r}$ & $\mathrm{R}^{2}$ & $r$ & $\mathrm{R}^{2}$ \\
\hline \multirow[t]{2}{*}{ Landbank } & 29 Jul 2004 & $-0.19^{*}$ & $-0.88^{* * *}$ & 0.90 & $-0.504^{* * *}$ & 0.255 & $-0.938^{* * *}$ & 0.881 \\
\hline & 5 Aug 2005 & $-0.41^{* * *}$ & $-0.72^{* * *}$ & 0.74 & $-0.629^{* * *}$ & 0.395 & $-0.819^{* * *}$ & 0.672 \\
\hline South Beach & 29 Aug 2004 & $-0.66^{* * *}$ & $-0.43^{* * *}$ & 0.95 & $-0.928^{* * *}$ & 0.862 & $-0.852^{* * *}$ & 0.726 \\
\hline \multirow[t]{2}{*}{ Deadman Bay } & 24 Sep 2004 & $-0.13^{*}$ & $-0.94^{* * *}$ & 0.95 & $-0.498^{* * *}$ & 0.248 & $-0.973^{* * *}$ & 0.948 \\
\hline & 6 Aug 2005 & $-0.37^{* * *}$ & $-0.77^{* * *}$ & 0.74 & $-0.625^{* * *}$ & 0.390 & $-0.858^{* * *}$ & 0.736 \\
\hline Cattle Pass & 19 Aug 2005 & -0.02 & $-0.89^{* * *}$ & 0.83 & -0.048 & 0.002 & $-0.871^{* * *}$ & 0.758 \\
\hline
\end{tabular}

\section{Current and bed size covariation during typical sampling windows}

One of the main objectives of this study was to quantify the short-term temporal covariation in both current velocity and Kelp Area that occurs during typical sampling intervals. As described above (see 'Materials and methods'), for each series we considered the sub-set of observations restricted to $\leq+1.2 \mathrm{~m}$ above MLLW. This analysis indicates a significant negative relationship $(p<0.05)$ between Kelp Area and current speed in 5 of the 6 time series (Fig. 4). The shape and strength of the relationship varied among sites; it ranged from a very strong $\left(r^{2}=0.97\right)$ linear relationship at South Beach in 2004 , to a strong $\left(\mathrm{r}^{2}=0.70\right)$ non-linear relationship at Deadman Bay in 2005, to weaker yet significant relationships $\left(\mathrm{r}^{2}=0.21\right.$ to 0.53$)$ in other series. The negative relationship between Kelp Area and currents was nonlinear at Deadman Bay in both years, whereas at other sites the decline appeared more linear. There was no obvious relationship between these variables at Cattle Pass in 2005, where currents were rarely strong.

\section{DISCUSSION}

Tidal currents and tidal height both had strong effects on the apparent size of the kelp bed measured using shore-based photography, suggesting that both factors could affect the accuracy of similar methods such as aerial photography. In general, the effect of tidal height was stronger than that of currents (Table 2). Moreover, tidal height consistently explained a large proportion of the variation in bed size at all sites on all sample dates (Table 2). Fortunately tidal height is extremely predictable and its effects consequently easy to control for by simply limiting sampling to a narrow time window around low tide (North et al. 1993). This approach is already used by several agencies in their aerial photography monitoring programs (Schoch 2001, Van Wagenen 2004).
Tidal currents also affected apparent bed size, but the strength (Table 2) and shape (Fig. 4) of this effect varied considerably among sites. Whereas the relationship between current speed and bed size was linear at South Beach and Landbank, it was non-linear at Deadman Bay. The Nereocystis luetkeana bed at Deadman Bay differed from the other 3 sites in that it tended to accumulate a large amount of drift algae, especially Fucus spp. and large mats of drift $N$. luetkeana. Drift algae became trapped in the bed, within the attached $N$. luetkeana, and was flushed out when currents picked up (authors' pers. obs.). Our image analysis technique was able to distinguish Fucus spp. from $N$. luetkeana because the 2 species differ considerably in color (light and dark brown, respectively) and therefore our bed size measurements do not include drift Fucus spp. However, there was no way to distinguish between attached and drift $N$. luetkeana in photographs, and consequently our bed size data undoubtedly include drift mats of $N$. luetkeana. We noted that this problem was especially evident at Deadman Bay. We suspect that the initially steep relationship between Kelp Area and current speed at Deadman Bay is related to the tendency of drift algae to become disentangled and evacuated quickly when currents pick up after slack tide. Kelp beds that experience protracted periods of low current, and particularly fringing beds, where current might not flush out drift material as easily, may be especially prone to this drift problem. In addition, the use of infrared techniques to record kelp beds, rather than the natural color techniques we employed, may be especially risky in these circumstances since the infrared reflectance signatures of many species of algae are similar (Guillaumont et al. 1997).

We must consider a limitation of our methodology while interpreting the detected negative relationship between current speed and Kelp Area: we measured currents only at a single point in space. We purposefully placed our current meter where we anticipated the strongest currents based on preliminary field 
South Beach (Aug 2004)

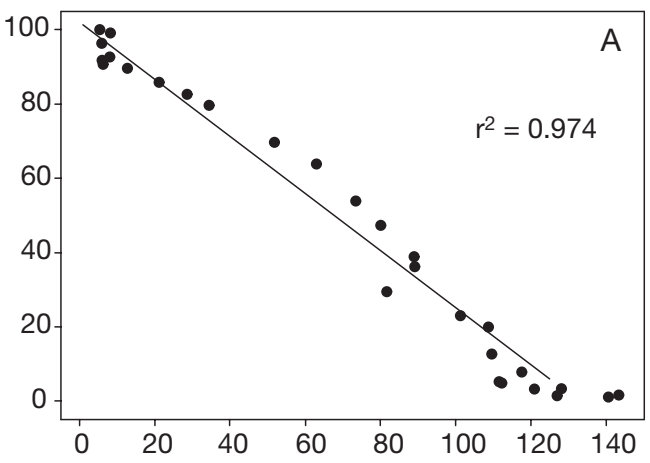

Deadman Bay (Sep 2004)
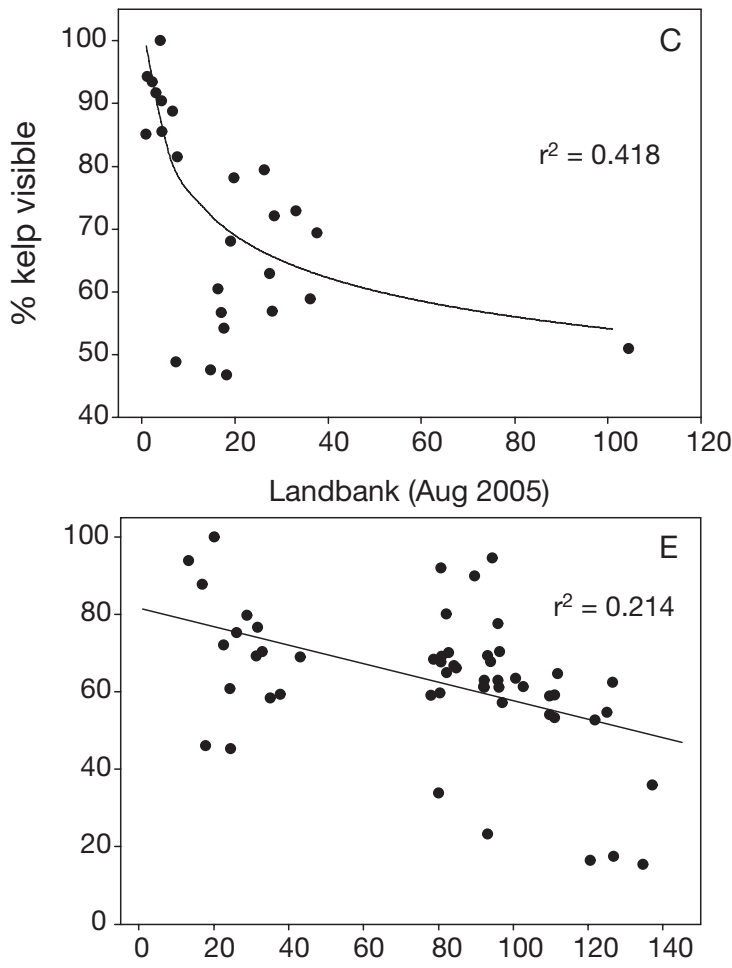

Landbank (Jul 2004)

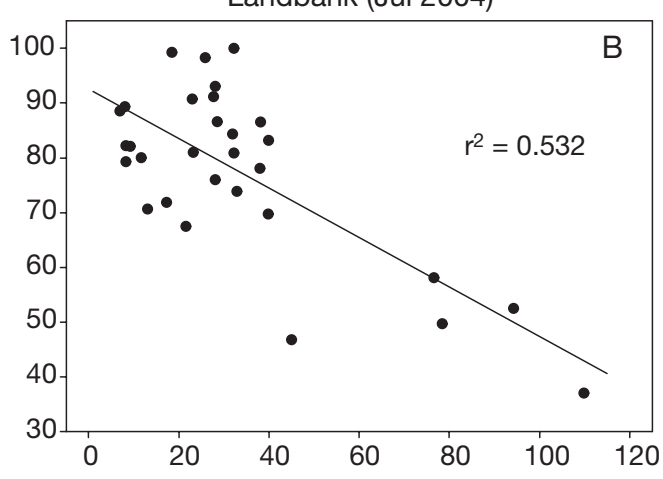

Deadman Bay (Aug 2005)
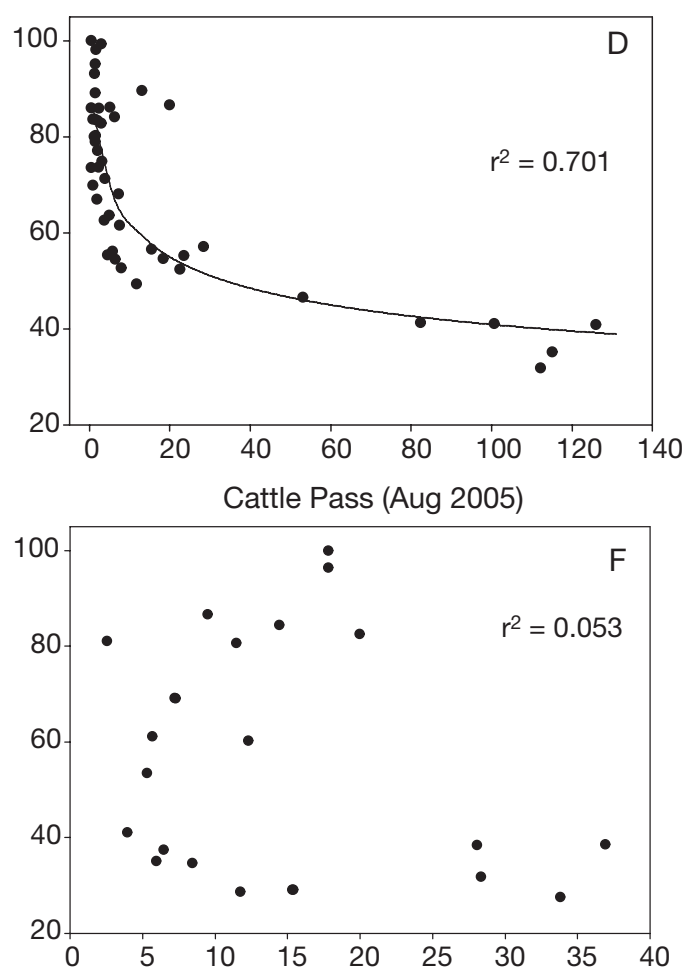

Current speed $\left(\mathrm{cm} \mathrm{s}^{-1}\right)$

Fig. 4. Relationship between percentage of Nereocystis luetkeana bed visible and current speed on 6 sample dates. These analyses were restricted to data between low tide and a tidal height of $+1.2 \mathrm{~m}$

observations (the center of the outer edge of the bed). However, water movement around a Nereocystis luetkeana bed is extremely complex and a single instrument cannot possibly capture the spatial variation in currents that exists. For example, at Landbank we often noted a weak back eddy on the inside of the bed that resulted in differences in the intensity and direction of currents on the inside and outside of the kelp bed. Spatial variation in current velocity would have produced a spatially 'average' current different from that which we measured. In fact, this source of 'error' related to our single point measurement would only weaken the apparent relationship between current speed and total bed size. Therefore, we expect that additional instrumentation that provided a better picture of the spatial variation in current velocity would have increased the power of our study and would have detected a stronger statistical relationship between current speed and bed size.

In contrast to tidal height, the effects of tidal currents on measured bed size will be much more difficult to account for when sampling from aircraft. Some might ar- 
gue that one could consult a current table to select a period of low currents in which to sample. However, our field observations suggest that currents close to shore (where most Nereocystis luetkeana beds occur) are often decoupled from current dynamics in the center of channels because of details in the shoreline topography and nearshore bathymetry. This is obvious in the various plots in Fig. 3, which show rapid fluctuations in current speed at most sites that are clearly decoupled from the tidal signal. For example, our Cattle Pass site is located near shore along a notoriously high-current channel, and based on current table predictions one would have expected a $5 \mathrm{~h}$ period of currents in excess of $100 \mathrm{~cm} \mathrm{~s}^{-1}$ and a maximum current velocity of $248 \mathrm{~cm}$ $\mathrm{s}^{-1}$ on the day we sampled that site (Mr. Tides version 2.5.6, based on NOAA tide predictions). In fact, during the flood tide we did witness a persistently strong northward current in the center of the channel that prevented many southbound boats from successfully navigating the pass. However, the currents in our Cattle Pass kelp bed were less than $20 \mathrm{~cm} \mathrm{~s}^{-1}$ during that same period. This discrepancy was caused by local topographic shading of our study site.

A second example of this decoupling phenomenon occurred at our Landbank site where the shoreline topography resulted in the creation of a large, persistent back eddy on the inside of the bed that was broken down by the main current at apparently random intervals during spikes in current velocity. Thus, at Landbank it was common for the inside of the bed to be experiencing a current that was weaker and in the opposite direction to that occurring on the outside of the bed. These examples highlight the complexity and unpredictability of nearshore currents and suggest that coarse current predictions designed for boaters will be of limited utility in surveys of nearshore kelp species. At sites where currents are strong and variable they could be a source of considerable error in size estimates of kelp beds derived from aerial photography. Methodologies that use infrared wavelengths will be especially susceptible to this problem because they have limited ability to detect kelp that have been subducted by currents (Austin \& Adams 1978, Augenstein et al. 1991, Guillaumont et al. 1997, Schoch 2001). However, red and green portions of the visible light spectrum are also ineffective at detecting subsurface kelp (Augenstein et al. 1991).

In this study we focused on the kelp Nereocystis luetkeana, but there are several other species of kelp that form floating canopies worldwide, including Macrocystis integrifolia, M. pyrifera, Alaria fistulosa, and many others. These species represent a wide range of morphologies, and interspecific differences in morphology are likely to have important implications for the relationship between current velocity and kelp bed size. For example, kelp species that are more positively buoyant than $N$. luetkeana should be less likely to be subducted by currents of a given velocity. In addition, there is considerable geographic variation in the physical habitats in which kelp beds occur. Nearshore habitats in our region are dominated by strong currents, and $N$. luetkeana is a species that is commonly found in high-current areas. Consequently, currents appear to be an important variable to consider for this species. Obviously, currents are unlikely to be a substantial source of error in areas where they do not reach high velocities. Rather than attempting to extrapolate our results broadly to different species and regions, we suggest that further studies are needed to evaluate the potential bias of currents (and tidal height) on size estimates of other kelp species in other regions of the world.

An important unresolved question is how our results compare to those that would be obtained if these studies were repeated using aerial photography. The view of plants using our oblique angle approach did not penetrate as deeply into the water column as would images taken from directly overhead (or at a much steeper angle) using aircraft (Guillaumont et al. 1997). Consequently, it is possible that the effect of currents on apparent bed size may be less severe when aerial methods are employed. A key issue that will determine the vulnerability of aerial methodologies to currentdriven variation in bed size is how effective the particular method is at detecting subsurface kelps. The ability to detect subsurface kelps will likely be affected by a large number of methodological issues that vary considerably among programs using aerial photography including flight altitude, photographic angle (both overhead and oblique methods are employed), and the spectral sensitivities of the photographic equipment. Moreover, temporally variable environmental parameters that cannot be controlled, including turbidity, the composition of suspended particulate matter (different types of particles have different absorption spectra), sun angle, glare, and light intensity, may cause temporal variation in the effectiveness of any particular method. Thus, assessing the relative sensitivity of various methods to current-driven subduction of plants would require empirically determined estimates of the depth at which subducted kelp are no longer detected by each method. Although some authors have provided crude approximations of the depth penetration of their methodology (e.g. Schoch 2001), to our knowledge none of the aerial methods currently employed have been assessed to empirically determine their effectiveness at detecting subsurface kelp.

Our oblique angle images mostly captured Nereocystis luetkeana stipes but not its blades, which are relatively thin and flat. Indeed, comparison of our 
shore-based photographs to 2 images taken nearly simultaneously by the Washington Department of Natural Resources in 2005 at our Landbank site indicate that our oblique-angle-corrected estimates of bed size are an average of $31 \%$ smaller than overhead estimates based on color infrared photography. This difference is probably attributable to our inability to consistently detect $N$. luetkeana blades in our images. However, we consider the gross similarity of estimates of bed size using oblique and overhead techniques to be encouraging; it suggests that our methodology reasonably captures apparent bed size.

To the extent that the motion of Nereocystis luetkeana stipes and blades are linked, our results should be similar to those obtained from overhead photography. However, there is at least one important way in which the motion of stipes and blades differs. At slack current, the distal ends of $N$. luetkeana stipes float at the surface, whereas the blades hang down limply into the water column (authors' pers. obs.). When there is a moderate amount of current the blades begin to stream out laterally, eventually pivoting upwards until they are at or near the surface. At high current velocity the entire thallus (blade and stipe) becomes subducted below the surface. When viewed from above, N. luetkeana beds may appear largest when there is a small amount of current that causes the blades to trail out. Beds might appear smaller under high- or no-current conditions. Given the large size of $N$. luetkeana blades, the difference in apparent bed size between no current and weak current could be substantial. This possibility should be investigated.

In summary, our results suggest that both tidal currents and tidal height have strong effects on apparent Nereocystis luetkeana bed area. Currents, in particular, are complex in the nearshore where bathymetric steering and topographic shadowing are potentially greatest, and are therefore unpredictable and highly variable both within and among sites. Our study photos, taken as little as 10 to 20 min apart, could reflect differences in current velocity as large as $100 \mathrm{~cm} \mathrm{~s}^{-1}$ at some sites (Fig. 3), with concomitant changes noted in $N$. luetkeana bed size. The effect of current on apparent kelp bed size is variable among sites and is likely influenced by the large number of site-specific characteristics such as maximum current velocity, bathymetry, and the shape of the shoreline (which will determine, for example, whether back eddies develop). Although these data demonstrate the potential bias of currents, further research is needed to quantify the influence of currents on kelp bed size estimates obtained using aerial techniques. More generally, this study highlights the need for quantitative studies of the effects of variation in environmental conditions on the accuracy of data obtained using remote sensing tech- nologies. Aerial photography is a potentially powerful monitoring tool, but in our view the use of this method has outpaced our understanding of its limitations.

Acknowledgements. We are grateful to H. Berry, N. Eckman, G. Foley, and D. Okamoto for assistance in the field. We especially thank J. Blanton of the Skidaway Institute of Oceanography and J. Jaffe of the Scripps Institute of Oceanography for loan of the S4 current meter and computer interface gear. This work was improved by discussions with H. Berry, T. Mumford, and K. Sebens. B. Blozcynski, H. Berry, and 2 anonymous reviewers made helpful comments on earlier versions of the manuscript. Funding for this study was provided by the Washington Department of Natural Resources and the Office of Naval Research. Laboratory space and boats were provided by Friday Harbor Laboratories.

\section{LITERATURE CITED}

Augenstein EW, Stow DA, Hope AS (1991) Evaluation of SPOT HRV-XS data for kelp resource inventories. Photogramm Eng Remote Sens 57(5):501-509

Austin A, Adams R (1978) Aerial color and color infrared survey of marine plant resources. Photogramm Eng Remote Sens 44(4):469-480

Berry HD, Mumford TF Jr, Dowty P (2005) Using historical data to estimate changes in floating kelp (Nereocystis luetkeana and Macrocystis integrifolia) in Puget Sound, Washington. Proc 2005 Puget Sound Georgia Basin Res Conf (available at: www.engr.washington.edu/epp/psgb/ 2005psgb/2005proceedings/papers/F7_BERRY.pdf

Carr MH (1983) Spatial and temporal patterns of recruitment of young-of-the-year rockfishes (genus Sebastes) into a central California kelp forest. MS thesis, San Francisco State University, CA

Deysher LE (1993) Evaluation of remote sensing techniques for monitoring giant kelp populations. Hydrobiologia 260/ 261:307-312

Dobson JE, Bright EA, Ferguson RL, Field DW and others (1995) NOAA Coastal Change Analysis Program (C-CAP): guidance for regional implementation. NOAA Tech Rep NMFS 123

Duggins DO (1980) Kelp beds and sea otters: an experimental approach. Ecology 61(3):447-453

Duggins DO, Simenstad CA, Estes JA (1989) Magnification of secondary production by kelp detritus in coastal marine ecosystems. Science 245(4914):170-173

Dunton KH, Schell DM (1987) Dependence of consumers on macroalgal (Laminaria solidungula) carbon in an Arctic kelp community: delta ${ }^{13} \mathrm{C}$ evidence. Mar Biol 93(4):615-625

Eckman JE, Duggins DO, Sewell AT (1989) Ecology of understory kelp environments. I. Effects of kelps on flow and particle transport near the bottom. J Exp Mar Biol Ecol 129:173-187

Eckman JE, Duggins DO, Siddon CE (2003) Current and wave dynamics in the shallow subtidal: implications to the ecology of understory and surface-canopy kelps. Mar Ecol Prog Ser 265:45-56

Ghelardi RJ (1971) Species structure of the animal community that lives in Macrocystis pyrifera holdfasts. In: North WJ (ed) The biology of giant kelp beds (Macrocystis) in California. Nova Hedwigia 32:381-420

Guillaumont B, Bajjouk T, Talec P (1997) Seaweed and 
remote sensing: a critical review of sensors and data processing. In: Round FE, Chapman CJ (eds) Progress in phycological research, Vol 12. Biopress, Bristol, p 213-282

Kvitek RG, Shull D, Canestro D, Bowlby E, Troutman BL (1989) Sea otters and benthic prey communities in Washington State. Mar Mamm Sci 5(3):266-280

North WJ, James DE, Jones LG (1993) History of kelp beds (Macrocystis) in Orange and San Diego Counties. Hydrobiologia 260/261:277-283

O'Neill NT, Miller J, Freemantle JR (1995) Atmospheric correction of airborne BRF to yield surface BRF: nomenclature, theory, and methods. Can J Remote Sens 21:309-326 Schoch GC (2001) The spatial distribution of bull kelp (Nere- ocystis luetkeana) in the Kachemak Bay Research Reserve. Kachemak Bay Research Reserve, Alaska Department of Fish and Game, Homer, AK

Sokal RR, Rohlf FJ (1981) Biometry, 2nd edn. Freeman and Company, San Francisco, CA

Tegner MJ, Haaker PL, Riser KL, Vilchis LI (2001) Climate variability, kelp forests, and the Southern California red abalone fishery. J Shellfish Res 20(2):755-763

Van Wagenen RF (2001) California coastal kelp resources, Summer 2000. Fin Rep, Monterey Bay National Marine Sanctuary, Monterey, CA

Van Wagenen RF (2004) Washington coastal kelp resources. Summer 2003. Fin Rep Washington Department of Natural Resources, Olympia, WA

Appendix 1. Trigonometric correction of kelp bed area estimates

Fig. A1 illustrates schematically the position of a camera elevated a distance $d_{\mathrm{V}}$ above sea level that views a small rectangular area offshore of dimensions $x$ (onshoreoffshore direction) and $y$ (along-shore direction, not shown). This area is located a horizontal distance $d_{\mathrm{H}}$ from the position of the camera. This cross-sectional perspective is not drawn to scale; the distances $x$ and $y$ are assumed to be extremely small relative to $d_{\mathrm{H}}$, and $\mathrm{X}$ is exaggerated here to increase clarity.

The true area $\left(A_{\text {true }}\right)$ of this small offshore rectangle is simply:

$$
A_{\text {true }}=x y
$$

However, because of the oblique view of the camera, $x$ has the apparent dimension $x_{\mathrm{a}}$ in the camera's field of view, and therefore the apparent area $\left(A_{\text {apparent }}\right)$ calculated from the photograph would be:

$$
\begin{gathered}
A_{\text {apparent }}=x_{\mathrm{a}} Y \\
x=x_{\mathrm{a}} / \sin \theta
\end{gathered}
$$

and $\theta$ is the angle of elevation of the camera above sea level:

$$
\theta=\tan ^{-1}\left(d_{\mathrm{V}} / d_{\mathrm{H}}\right)
$$

The distances $d_{\mathrm{H}}$ and $d_{\mathrm{V}}$ (reported in Table 1 for each site) were calculated from geo-positions obtained using hand-held GPS units.

Photographic distortion in dimensions is relevant to the $x$ dimension only. There is no significant distortion in dimension $y$ recorded by the camera because the scale bar that was placed within the field of view to calibrate images trailed along-shore in the $y$ dimension.

Combining Eqs. (A1) through (A3) one obtains:

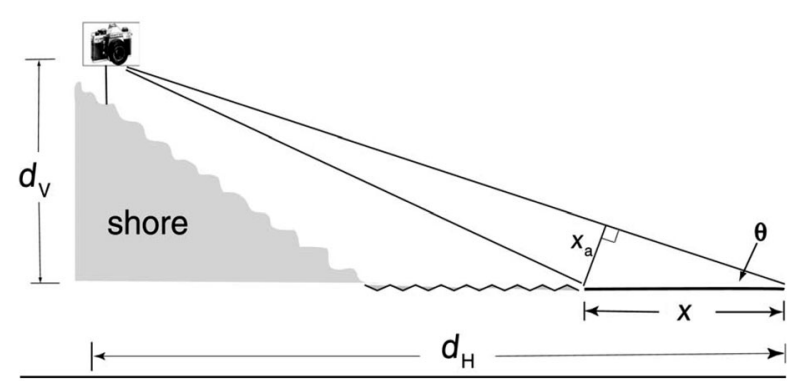

Fig. A1. Schematic representation of a camera mounted at an elevated position on shore viewing an offshore kelp bed.

Only the onshore-offshore dimension is illustrated

$$
A_{\text {true }}=x_{\text {a }} y / \sin \theta=A_{\text {apparent }} / \sin \theta
$$

Thus, the apparent area calculated from an obliqueangle view must be divided by $\sin \theta$ to estimate the true area.

Finally, it is worth considering the error involved in assuming that a single linear scale (defined by the scale bar in the photograph) applies to all locations within the field of view of the camera. The potential error is greatest in the onshore-offshore dimension. However, bed size in this dimension typically was 10 to $15 \mathrm{~m}$. This is a small fraction $(<13 \%)$ of the distance of the kelp bed from the camera (123 to $443 \mathrm{~m}$, Table 1). Therefore the magnitude of error introduced by this assumption is similarly small. In addition, since the location of the bed, the camera, and the scaling factor were all fixed for each time series, the error was effectively constant in all estimates of bed area at each site. Thus, this error should not influence our analysis of the effects of tidal height and current speed on apparent kelp bed size. 